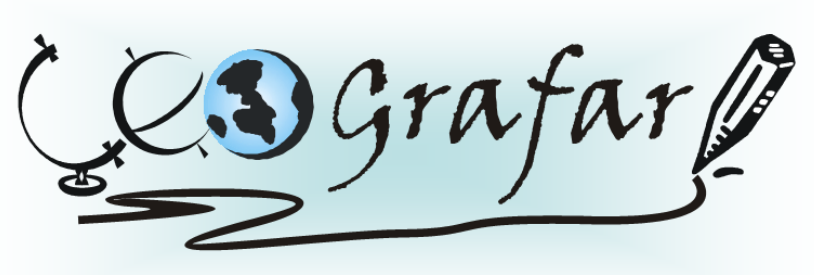

Revista Eletrônica do Programa de Pós-Graduação em Geografia - UFPR

ENTRE IMAGENS E DEVOÇÕES:

A PESQUISA GEOGRÁFICA NAS FESTAS DE HOMENAGEM A XANGÔ

\author{
BETWEEN IMAGES AND DEVOTIONS: \\ THE GEOGRAPHICAL RESEARCH IN THE TRIBUTE TO XANGÔ PARTIES
}

\author{
Rogério Amaral Pereira \\ Doutorando em Geografia \\ Universidade Federal do Paraná \\ Curitiba, PR, Brasil \\ e-mail: rogerioappixote@hotmail.com
}

\begin{abstract}
RESUMO
Este artigo aborda o estudo de caso de duas festas em homenagem ao Orixá da Justiça, Xangô, realizadas no mês de setembro de 2013, as quais compõem as investigações de campo no doutorado, ainda em andamento. Esta leitura sobre os eventos festivos religiosos, objetiva contextualizar o uso da imagem fotográfica de primeira ordem, na pesquisa em Geografia Humana. E compreender a fotografia como aporte metodológico na pesquisa qualitativa. Neste sentido, o artigo é resultado de reflexões concernentes às observações em dois Terreiros de Umbanda da cidade de Rio Grande-RS-Brasil: o Centro Espiritualista "Reino de São Jorge" CERSJ, e o Centro Espiritualista "Tenda de São Jorge" - CETSJ. Sob as contribuições teóricas da Geografia, da Filosofia, da Antropologia e da Sociologia. Assim, a exposição do tema apresenta-se organizada em duas etapas: a primeira visa verticalizar a abordagem das imagens sobre os lugares onde a devoção é exaltada; a segunda realiza uma reflexão sobre as imagens fotográficas como conhecimento. Nesta perspectiva, o subsídio social do estudo, é permitir uma leitura acadêmica e desprovida de prejuízo, ao manusear cientificamente a festa de cunho religioso através do registro fotográfico in loco.
\end{abstract}

Palavras-chave: Geografia Humana; pesquisa qualitativa; fotografia; Terreiros de Umbanda; evento religioso. 


\begin{abstract}
This article covers the case study of two parties in tribute to the Justice Orixá, Xangô, performed in September, 2013, which compose the field investigations in the doctorate, still in progress. This reading about the religious festivities, aims to contextualize the use of the first order photographic image, in the research in Human Geography. And understand the photography as a methodological contribution in the qualitative research. In this sense, the article is a result of reflections related to observations in two Terreiros de Umbanda in Rio Grande -RS - Brazil: The Spiritualist Centre "Reino de São Jorge" - CERSJ, and the Spiritualist Centre "Tenda de São Jorge" - CETSJ. Under the theoretical contributions: of Geography, of Philosophy, of Anthropology and of Sociology. In this way, the exposition of the subject is organized in two steps: the first step aims the verticalization of the approach of the images in the places where the devotion is exalted; and the second step makes a reflection about the photographic images as knowledge. In this perspective, the social allowance is to permit an academic reading and without losses, during the scientific analyze of a religious party through the photographic register in loco.
\end{abstract}

Keywords: Human Geography; qualitative research; photography; Terreiros de Umbanda; religious festivity.

\title{
1. INTRODUÇÃO
}

Um dia, então - como a borboleta que rompe sua crisália -, a imagem estoura, cintila por um breve instante, antes de levantar voo, de desaparecer momentaneamente. Ela parte. Ela se dissolverá talvez, ou será esquecida, dentro de seu tempo histórico. Nunca, todavia, se perderá. Quando a reencontrarmos, dez ou mil anos mais tarde, quando ela se representará aos olhares [...] (SAMAIN, 2012, p.33-34).

E nesta esfera de ares poéticos do texto de Etienne Samain sobre o proclamar das imagens fotográficas, o estudo apresenta a experiência em dois trabalhos de campo realizados para confecção da Tese, no Programa de PósGraduação em Geografia, da Universidade Federal do Paraná - UFPR. Assim, O objetivo é contextualizar o uso da imagem fotográfica de primeira ordem ${ }^{1}$ no campo da Geografia Humana.

Para isto, adentrou-se no universo festivo devocional de Xangô no encontro com as manifestações humanas, sobre a temática cultural religiosa. Esta foi

\footnotetext{
${ }^{1} \mathrm{O}$ autor descreve as imagens fotográficas captadas em trabalho de campo pelo próprio pesquisador.
} 
procedida com a pesquisa in loco em dois Terreiros ${ }^{2}$ de Umbanda na Cidade de Rio Grande - RS - Brasil: o Centro Espiritualista "Reino de São Jorge"- CERSJ, e o Centro Espiritualista "Tenda de São Jorge"- CETSJ, (ver FIGURA 1).

$A$ atividade de investigação nestes lugares, onde o sagrado é exaltado, foi exercida durante o segundo semestre do ano de 2013. Com isto, as abordagens geográficas apresentam o vivenciar do tempo festivo de Xangô nos dois grupos sociais religiosos, assentados nos espaço simbólicos sacralizados dos Templos Umbandistas. E, no limiar das manifestações religiosas, a experiência com uso da fotografia. Ela apresenta, como desígnio, salientar elementos simbólicos que, por meio só da escrita não seria possível abarcá-los devido a seu dinamismo.

Para isto, as reflexões do estudo foram exercidas através das atribuições teóricas de: Malinowski (1976), no trabalho de campo do pesquisador; Eliade (2010), sobre o mito e a realidade na religião; Dardel (2011), na geografia mítica; Gomes (2013), nas espacialidades das imagens; Cervo e Bervian (1978); Crizzotti (1995); Bonsack (2010); Samain (2012), para a compreensão e reflexões das imagens fotográficas de primeira ordem; e Bourdieu (2009, 2013), no uso das imagens no trabalho de campo e para o entendimento no campo religioso; entre outros autores.

Entretanto, as imagens captadas, as opiniões em relação aos símbolos no estudo foram apontadas sob o olhar geográfico para o viés religioso cultural da Umbanda. Assim como "preposição" na forma de texto capitulado, com ação e vivacidade, associado ao campo formado no entorno da religião e da religiosidade ${ }^{3}$, onde suas espacialidades e símbolos contemplam a visão endógena, do movimento de compreensão que, com a fotografia, foi plausível abordar.

E, a fotografia como instrumento de comunicação é também compreendida, segundo Bourdieu (2009), como ferramenta de conhecimento dos grupos sociais e dos seus lugares de pertencimento, não deslembrando que a mesma torna-se, em alguns casos, veículo de sustentação simbólica estruturante.

$E$, no seu estilo perturbador, as fotografias aguçaram questionamentos para pesquisa: Como esta técnica metodológica qualitativa ganha vida e movimento? Como remetem a localizações, formas espaciais, territorialidades, paisagens e

\footnotetext{
${ }^{2}$ No decorrer do estudo, o termo será referido com letra maiúscula inicial como sinal de respeito ao local de manifestação religiosa de matriz afro-brasileira.

${ }^{3} \mathrm{O}$ termo apontado tem $\mathrm{o}$ sentido de referir-se à vivenciação equilibrada de todos os momentos da nossa vida.
} 
lugares e aos modos como os seres humanos se manifestam coletivamente e individualmente na sociedade, dinamizando seus costumes em forma de cultura? Para isto, o estudo, também, aborda a reflexão a respeito da linguagem (re)apresentada na imagem fotográfica de primeira ordem. Por isto é fundamental para o estudo da espacialidade no campo denominado social, na forma de registrar o olhar perante os objetos culturais e os atores sociais que os compõem, neste caso, o universo devocional da Umbanda.

Deste modo, a exposição do tema foi organizada em duas etapas: a primeira visa verticalizar a abordagem sobre os espaços onde a devoção é exaltada; e a segunda realiza uma reflexão sobre as imagens fotográficas como conhecimento. É realizada, por meio da ponderação das fotografias captadas durante as festividades de homenagem a Xangô, ${ }^{4}$ a compreensão dos símbolos religiosos espacializados.

Com isto, procurou-se alcançar a afinidade do homem com o meio (ambiente), e o que ele traz de subjetivo na relação com o espaço - que é a liberdade expressada na cultura. No modo de interpretar as interações do "Ente" e do "Ser" com a natureza e com o próprio homem que também ergue seus símbolos por meio da "constituição do mundo através das imagens" (BONSACK, 2010, p.115). $E$, para isto, efetivaram-se esforços para verticalizar o estudo sobre as "espacialidades do sagrado" que começam no imaginário humano e tomam forma de símbolos através do campo religioso (BOURDIEU, 2009).

Mas aqui quer-se deixar com a reflexão metodológica na utilização de fotografia de primeira ordem - sem ter a convicção de parecer uma pretensão exagerada - um organizar de ideias, que permita operacionalizar a técnica na Geografia Humana. Esta foi constituída por meio de uma longa trajetória, cuja composição está fundamentada por meio de observações e de estudos como este, que será oferecido no decorrer dos próximos parágrafos.

\footnotetext{
${ }^{4}$ Orixá deus dos raios, relâmpagos e travões. Tem as cores vermelhas e brancas nas suas representações. As suas datas são comemoradas nos dia 29, como São Miguel e 30 de setembro, como São Jerônimo.
} 
Entre imagens e devoções: a pesquisa geográfica nas festas de homenagem a Xangô.

FIGURA 1 - LOCALIZAÇÃO DOS TERREIROS PESQUISADOS NO MUNICÍPIO DE RIO GRANDE NO RIO GRANDE DO SUL.

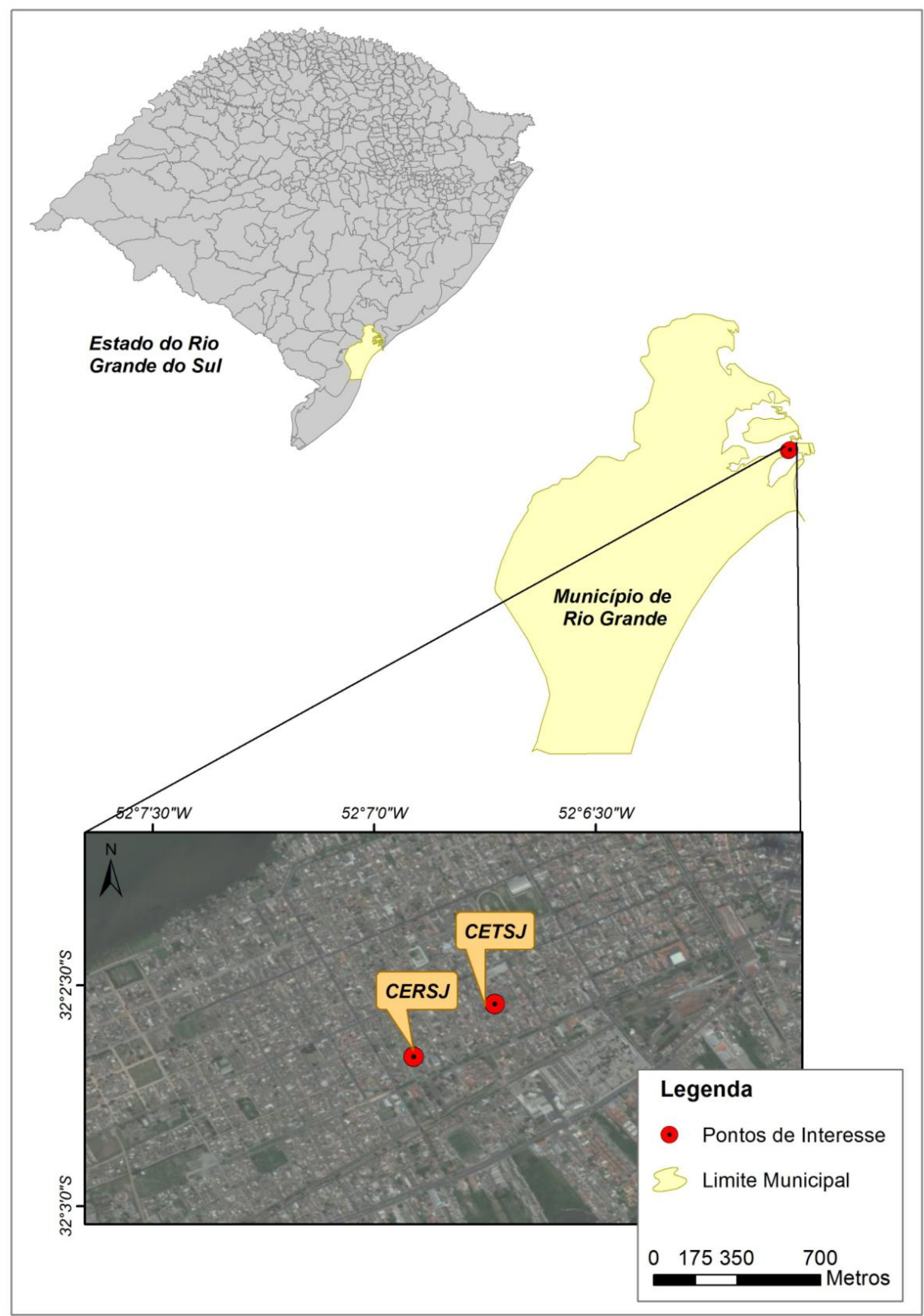

FONTE: BASE CARTOGRÁFICA IBGE, (2014). ORGANIZADO PELO AUTOR, 2014. 


\section{UM OLHAR GEOGRÁFICO: A FOTOGRAFIA NO EVENTO RELIGIOSO}

Xangô e seus homens lutaram com um inimigo implacável. Os guerreiros de Xangô, capturados pelos inimigos, eram multilados e torturados até a morte, sem piedade ou compaixão. As atrocidades já não tinham limites. O inimigo mandava entregar a Xangô seus homens aos pedaços. [...]. Xangô estava irritado e começou a bater nas pedras com o oxé, bater com seu machado duplo. [...]. A guerra perdida foi se tornando vitória. [...]. Mas os soldados inimigos que sobreviveram foram poupados por Xangô. A partir daí, o senso de justiça de Xangô foi admirado e cantado por todos (PRANDI, 2001, p. 245).

E neste cenário mitológico, Reginaldo Prandi sobre o reconhecimento de Xangô como Orixá da justiça, salienta aspectos e simbolismos da devoção, rememorado nos Terreiros e também no cotidiano do indivíduo ou grupo social religioso. E a sua presença é compreendida como algo qualitativamente superior. Assim, a experiência religiosa repercute em diferenciações em relação aos lugares e objetos, ou seja, o machado deixa de ser uma ferramenta e torna-se a presença da divindade no local em que se encontra ligado ao vivenciar o espaço simbólico. E os seres humanos, além de sacralizarem os objetos e os lugares, necessitam vivê-los, pois se percebe o lugar à volta, o Terreiro construído, o local reservado, a sua potencialidade. Eliade (2010, p.16) esclarece a relação dos mitos com as festas na religião, do seguinte modo:

Os mitos, efetivamente, narram não apenas a origem do Mundo, dos animais, das plantas e do homem, mas também de todos os acontecimentos primordiais em consequência dos quais o homem se converteu no que é hoje [...]. Se o Mundo existe, é porque os Entes Sobrenaturais desenvolveram uma atitude criadora no "princípio". Mas após a cosmogonia e a criação do homem ocorrem outros eventos, e o homem, tal qual é hoje, é o resultado direto daqueles eventos míticos, é construído por aqueles eventos.

E o incluir do fator religioso na festa como uma linguagem (sacralizada), esta fruto da relação mítica, permite alcançar uma afinidade de símbolos que deixa atrás a superação de uma vertente positivista de mera dicotomia entre a dualidade corpo e alma, simbolismo e racionalidade, mito e logos, sagrado e profano, pois é dentro destas forças dialéticas que interagem de modo produtivo e constitui o campo imagético ${ }^{5}$. Então, a imagem fotográfica funciona como veículo de exibição, no qual a "visibilidade depende da morfologia do sítio da existência de um público e da

\footnotetext{
${ }^{5} \mathrm{O}$ termo refere-se como um Eu que se torna um ponto de reflexo que vê, mas não se deixa ser visto, o qual não possui ponto nem ocupa um espaço, é exercido pela própria mente fenomenológica.
} 
produção de uma narrativa [...], a pessoa ou fenômeno encontra sentido e merece destaque" na sua devoção (GOMES, 2013, p. 92).

Portanto, os símbolos misturam as percepções humanas, porque assumem 0 lugar dos acontecimentos verdadeiros (FOTO 1). Eles apresentam-se como a crença e, mais, a existência de um lugar para preenchê-la no inconsciente individual, o qual aceita a compreensão dos processos que produzem a necessidade da sublimação religiosa. Ainda assim, este processo existe com o indivíduo, não podendo preencher esse lugar com suas próprias produções, mas somente utilizando significantes dos quais não dispõe livremente.

Conforme Dardel (2011, p. 55):

Esses lugares, bem entendido, não são divindades por eles mesmos; porém é neles que "tem lugar" a hierofania, e ela continua a ser algo, um tipo de sortilégio mágico ou de emancipação mítica. Por isso endereçamos nossas preces em sítios consagrados.

Bourdieu (2009) expõe que determinados símbolos são perpetuados, entre outras palavras, obtendo destaque social em relação a outros. Ele também enfatiza que determinados símbolos, através da sua "linguagem", têm, como dinâmica de informação, destacar os grupos sociais. E, neste conjunto de ideias alavancadas pela questão do símbolo, despontou o seguinte questionamento: Como a(s) festa(s) de Xangô é(são) abarcada(s) como um símbolo e não como um signo de uma religiosidade?

FOTO 1 - SIMBOLOGIA RELIGIOSA DE XANGÔ NO CERSJ.

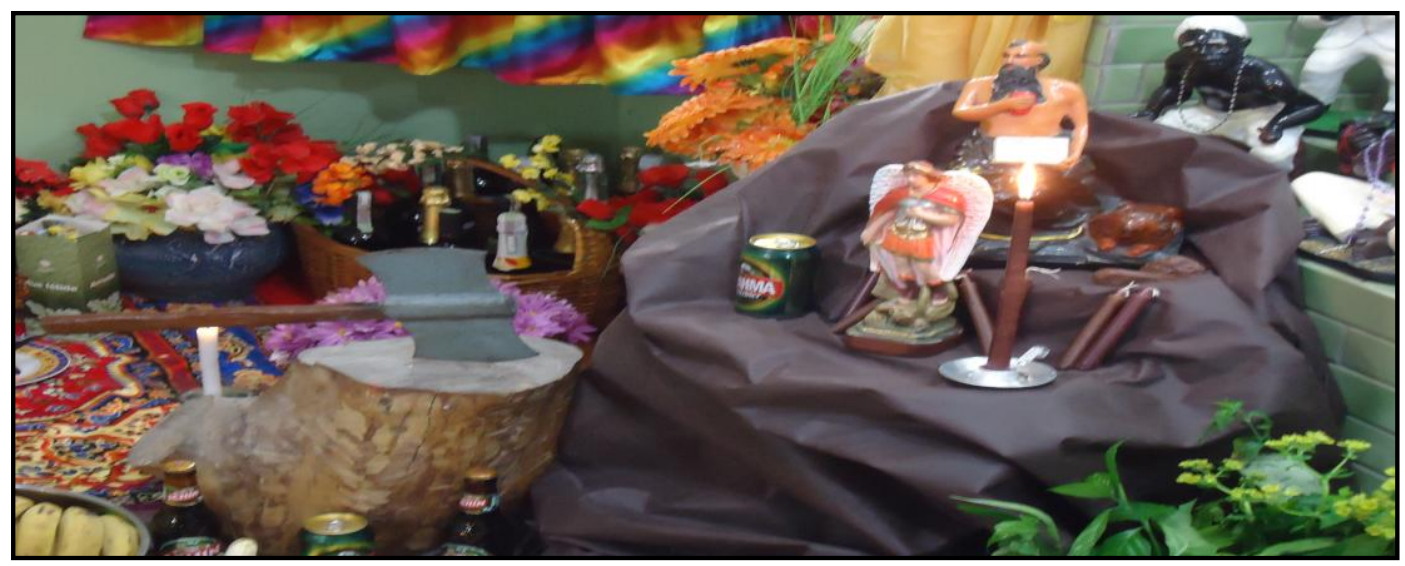

FONTE: ACERVO DO AUTOR, 2013. 
Para Eliade (2010), uma vez que, quanto mais forte é a tendência dos homens para crer em um poder invisível e inteligente presente na natureza, mais eles têm uma tendência igualmente forte de dar atenção aos objetos sensíveis e visíveis e, a fim de reconciliar essas inclinações, são levados a unir o poder invisível a algum objeto visível, a exemplo, das esculturas religiosas e do machado (FOTO 1).

Neste panorama, destaca-se a questão do objeto festivo também representar o simbólico. E de apresentar dois contemplares nítidos e fixos, que envolvem o cenário festivo: o natural (devoção) e o religioso-cultural (os símbolos que representam o vivenciar do tempo de Xangô) (FOTOS 2 e 3). Com o vivenciar da linguagem religiosa dos rituais pelos médiuns, antes da festa, na comunicação de um plano que os remete à espacialidade da divindade religiosa.

FOTO 2 - VIVÊNCIA RELIGIOSA DOS MÉDIUNS NO TEMPO FESTIVO DE XANGÔ NO CERSJ.

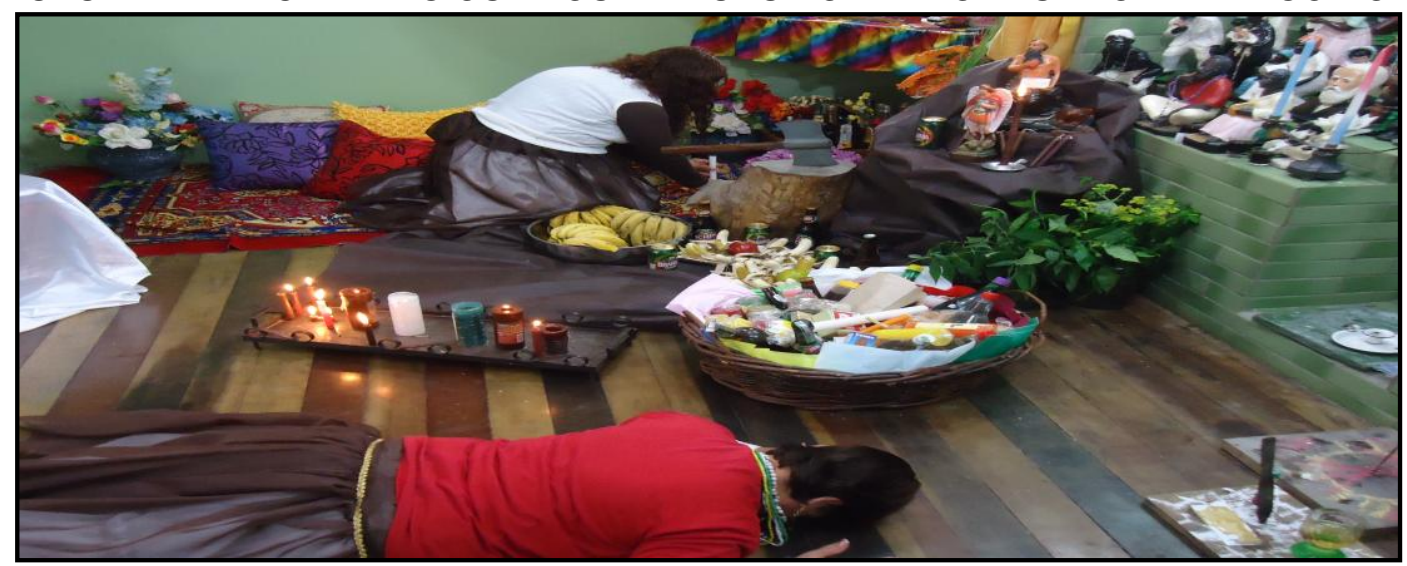

FONTE: ACERVO DO AUTOR, 2013.

FOTO 3 - CONCENTRAÇÃO DO MÉDIUM PERANTE O CONGÁ ANTES DA FESTA NO CERSJ.

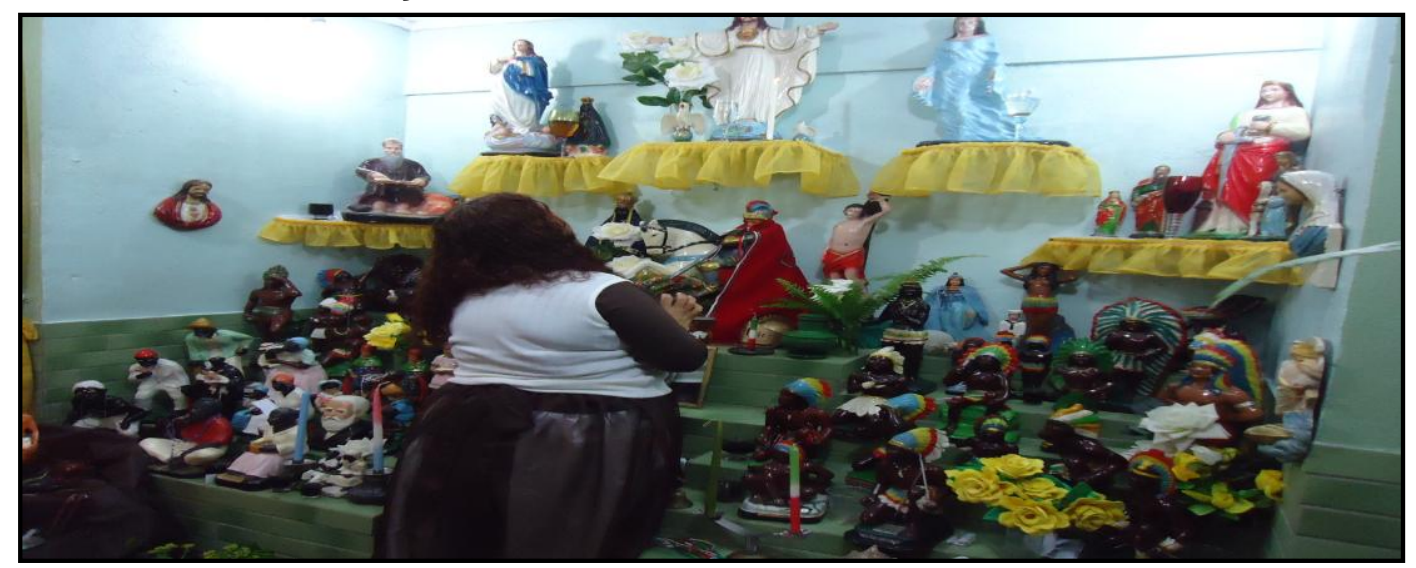

FONTE: ACERVO DO AUTOR, 2013. 
Deste modo, os Terreiros abrirem suas portas ao público às 20 horas, no dia 22 do mês de setembro, no CERSJ, e no dia 20 do mesmo mês em 2013, no CETSJ, com a proposta em suas atividades religiosas de saudar o universo mítico e religioso do Orixá da Justiça e das Pedreiras, Xangô. Nesta narrativa, a festa religiosa tornou-se o saber que significa apreender o mito central, ou seja, o "homicídio" da divindade e suas consequências é esforçar-se por jamais esquecê-la (ELIADE, 2010).

Com isto, as pessoas dirigiam-se aos bancos em estado de plena concentração e outras ainda davam sequência aos assuntos mundanos; e mais, tentavam passar mensagens ou telefonar antes do começo das atividades religiosas. E mesmo na Assistência ${ }^{6}$, as que tinham suas guias (colares) deixavam-no para fora de suas vestes como forma de reverenciar a(s) Entidade(s) pertencente(s), e para receberem as vibrações positivas oriundas do Congá 7 .

E com as cortinas ainda fechadas, apresenta, no CETSJ e no CERSJ, a pequena cerca de madeira na altura de 1 metro, pintada na cor verde, a qual estabelece um limite entre os dois ambientes, a Assistência e o Salão nos Terreiros, ou seja, o limite entre o grupo com iniciação religiosa e o grupo leigo. Constitui assim uma relação de poder daquele que tem a linguagem religiosa e seus fundamentos perante aquele (leigo) que vai ao encontro dele para estabelecer um diálogo com a Entidade Espiritual. E no espaço sacralizado do Salão onde ocorre grande parte dos trabalhos religiosos, a exemplo da incorporação dos médiuns, entre outros, as orações e pontos cantados.

Os médiuns arrumam-se com as vestimentas, nos vestiários localizados no lado do Salão e, um a um, logo após terminarem a sua arrumação, antes de começarem as atividades religiosas, eles se concentram em uma roda, e realizam orações e reforçam os pedidos de bons trabalhos espirituais para todos os médiuns da Corrente. E depois desta reunião, deslocam-se para ao Salão. E perfilados um a um, saúdam o Congá, esticando seus corpos na horizontal (FOTO 2), com os braços para cima, batem a cabeça três vezes no solo e dirigem-se para o seu local no salão.

\footnotetext{
${ }^{6}$ Local nos Terreiros de Umbanda destinado ao público consulente.

${ }^{7} \mathrm{O}$ termo refere-se ao ponto onde se contempla as imagens no Terreiro com mensagens (oferendas), local onde os médiuns fazem a concentração e pedem energia, pois a maior força. Por ser referente a um altar, é o local onde é criado um magnetismo no plano terreno, no qual as divindades "descem" e ocupam todo o espaço reservado para as práticas religiosas.
} 
E a Dirigente Espiritual da Casa fica na frente do Congá, de dianteira para a imagem da entidade Guia de seus trabalhos religiosos junto aos médiuns mais graduados. Deste modo, os médiuns compõem um semicírculo, todos voltados para o Congá, os mais novos de joelhos e os mais velhos em pé durante as orações que iniciam os rituais.

\footnotetext{
Nesse mundo mítico, onde a pessoa individualmente não possui "existência", onde o indivíduo só é como parte de um todo, membro de um clã, depositário de uma função, a Terra é a base do sujeito coletivo, o suporte concreto da essência permanente e invisível atualizada no grupo vivo religioso (DARDEL, 2011, p.56).
}

De tal modo, as velas acesas, as fumaças emitidas dos defumadores, as bebidas ofertadas pelos contemplativos apresentadas nas cerimônias (FOTO 4), representam mais que um simples ato devocional. Estes elementos traduzem a relação do(s) indivíduo(s) religioso(s) na comunicação com as divindades do panteão da Umbanda e suas espacialidades religiosa e cultual. E cada ambiente do local religioso emana uma simbologia.

Portanto, este tempo festivo nos Terreiros visitados também é compreendido, segundo Eliade (2010, p. 30), "como uma porta para o alto, por onde os deuses podem descer à Terra e o homem pode simbolicamente subir ao Céu".E, no Congá, local onde as velas, as bebidas ofertadas às entidades $e$ as plantas que ornamentam e apresentam um simbolismo, que misturam cheiros e odores específicos desse ambiente, nota-se o tipo de oferenda realizada e para a divindade em questão, contemplando a espacialidade do seu tempo mitológico festivo.

FOTO 4 - ENTRADA DO PÚBLICO DEVOTO NO ESPAÇO SACRALIZADO DO SALÃO NO CETSJ.

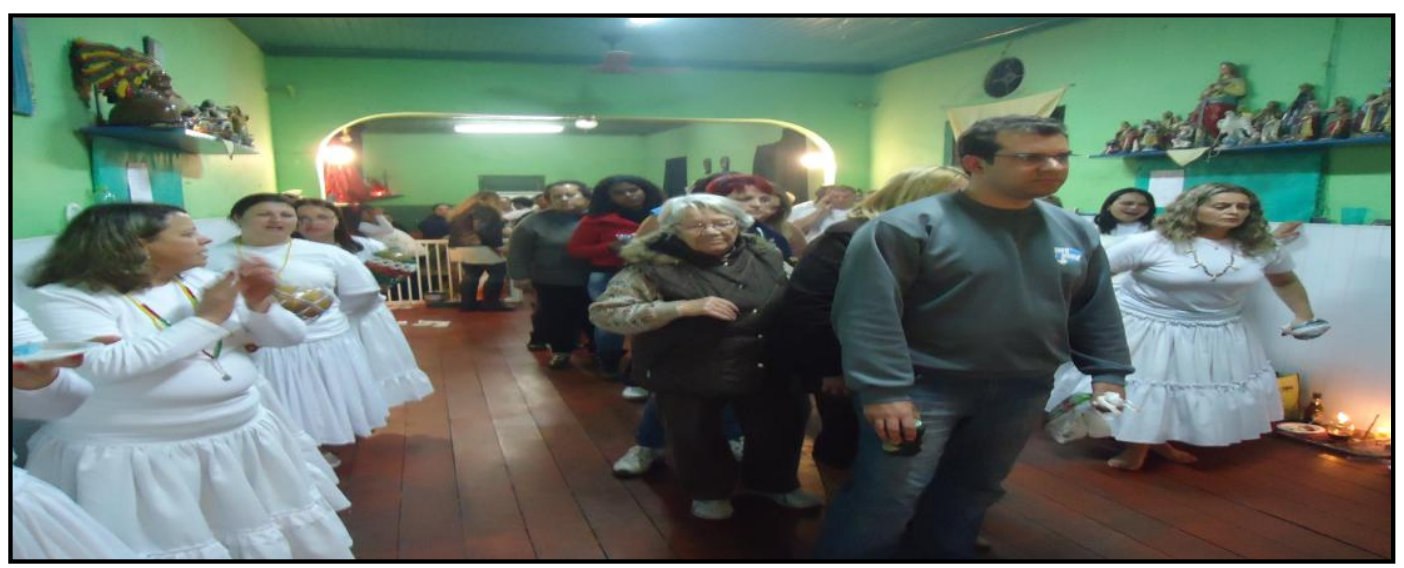

FONTE: ACERVO DO AUTOR, 2013. 
Contudo, na concepção do grupo religioso nestas festividades, fazer parte do "mundo" divino de Xangô é possuir um local semelhante ao do seu, através dos seus rituais, aromas e cheiros. É remeter ao templo sagrado, as festas, na grande maioria periódica, as quais representam os atos realizados pelos seres divinos.

Com isto, o homem torna-se contemporâneo das divindades, quando ritualiza as obras divinas, imitando gestos e ações. Assim as imagens fotográficas de primeira ordem exibidas procuraram dialogar com os autores para uma reflexão sobre o plano mítico religioso do Orixá da Justiça na Umbanda.

\title{
3. IMAGEM FOTOGRÁFICA É CONHECIMENTO
}

A ciência geográfica também centra seus estudos nas estruturas e interações do homem com o ambiente. Ela recebe a denominação do seu objeto de estudo, de espaço geográfico. Assim, as interações humanas, também fruto da cultura, podem ser analisadas sob o seguinte viés: o da materialidade e o da imaterialidade. E eles vão ao encontro do que na filosofia platônica aponta como mundo material e plano imaterial. O último citado é visto como mundo das ideias, e também a morada das divindades. E, nesta relação, o espaço como concreto (palpável) é representado pela vida cotidiana como fenômeno que, em parte, é captado e representado através da imagem fotográfica.

\begin{abstract}
A imagem é um fenômeno na medida em que é, com efeito, o resultado de um processo que combina aporte dos mais variados. Tomemos como exemplo a imagem fotográfica. A que processo combinatório ela deve sua existência? Para moldar, precisou de um suporte uma máquina captadora de luz, jogos de lentes, diafragma e obturador, uma placa sensível. Para se construir, precisou de uma pessoa, do seu talento, de sua maneira de observar, de pensar e de expressar o que viu de enquadrar, de retocar, de manipular. Para emergir, ela precisou da existência do tempo, do espaço, da luz e da sombra, das cores, das linhas, dos volumes, das formas, do ambiente, em poucas palavras, da longa história de um assunto/motivo icônico que parece não ter fim (SAMAIN, 2012, p.30).
\end{abstract}

A fotografia pensada como fenômeno é envolvente, atuante, ou seja, um texto que emite uma linguagem através de códigos singulares e, muitas vezes, díspares, de um "espaço livre". No entanto, as mensagens necessitaram também da compreensão do universo investigado, neste caso, as festas de homenagem a Xangô. Contudo, foi possível mencionar que a fotografia na pesquisa qualitativa é 
um elemento técnico primordial, pois no processo de construção do conhecimento favorece a leitura e a compreensão de uma "geograficidade" (DARDEL, 2011).

Isto acontece na sua forma de exposição, seja ela na forma bidimensional ou tridimensional. Esta última citada, devido aos aparatos técnicos da atualidade, expõe e ressalta elementos do objeto de pesquisa, ocultos a uma simples visada pelo pesquisador, mas que apresenta muito da sua subjetividade humana, "ao método adequado para observar e registrar estes aspectos imponderáveis da vida real" (MALINOWSKI, 1976, p. 35). Assim, a fotografia funciona e "fornece ao pesquisador o esquema mental que the serve de apoio e permite estabelecer o roteiro a seguir em seus trabalhos" (Idem, p. 29).

$E$, no roteiro seguido pelas fotografias, destaca-se que o capitular das imagens em campo auxiliaram, muitas vezes, mais que páginas de descrições, e remeteram às sequências de um acontecimento. Elas operam como o ordenamento de uma Geografia que se faz presente diante dos olhos do pesquisador, esta, pelo viés da cultura e da religião.

Todavia, a construção e a compreensão das fotografias de primeira ordem é uma técnica de pesquisa qualitativa, pouco debatida e, por isto, não apresentada de forma verticalizada na metodologia das pesquisas em Geografia Humana. No modo, a fotografia torna-se um adorno, às vezes sem vida e muito menos sem diálogo nos textos. Mas, deve-se ressaltar que a fotografia ocupa-se em prestar as mais diversas e importantes informações sobre o espaço geográfico, ou seja, na sua relação com o espaço, com o tempo e com o homem na sua mais íntima forma de atuação social revela e reforça espacialidades simbólicas.

E nesta relação geográfica, as espacialidades expostas pelas imagens fotográficas exigem o refino no olhar do pesquisador, pois, ao observar o que não é apresentado de maneira explícita no primeiro olhar, é aceitável apenas decodificar a sua reprodução por meio de uma mística que envolve sentimentos de arte com cientificidade e a fotografia torna-se esta magia conflitante de emoções passadas que auxiliaram a interferir ou construir o presente. E, neste complexo, são evocados os mais variados sentimentos humanos.

Deste modo, a imagem fotográfica apresenta-se estática no seu aspecto físico. Mas na sua forma de compreensão, ela surge dinâmica e potente na circulação de mensagens que encaminham aos mais variados pensamentos 
transcendidos do reticulado do seu espaço físico aprisionado, em muitos casos, ao papel.

A compreensão desta realidade ocorre pela observação do meio, onde se encontram os atores sociais que a compõem, neste caso, dos referidos Terreiros de Umbanda. Então, as seguintes questões foram expostas: Como captar esta realidade que se apresenta de modo devocional a todo o momento para o grupo religioso, mas que, muitas vezes, em campo expõe-se como algo fugaz, e não é dado interesse pelo pesquisador, no primeiro instante? $E$, por outro lado, como a fotografia pode contribuir para explicação das suas inquietudes cientificas?

Cientificamente, o número esmagador de produtos evidencia a linguagem escrita, como balizadora das investigações de campo. Esta alicerçada na técnica em campo das entrevistas abertas, fechadas ou semiestruturadas, realizadas com um gravador e um questionário em mãos pelo pesquisador. Direcionam-se ao encontro de um novo mundo, no qual o pesquisador se insere e descobre algo novo a cada momento. Isto também é possível com a fotografia junto à linguagem escrita, ou seja,

[...] estudar tudo aquilo que mais intimamente lhe diz respeito, ou seja, o domínio que a vida exerce sobre ele. Cada cultura possui seus próprios valores: as pessoas têm suas próprias ambições, seguem a seus próprios impulsos, desejam diferentes formas de felicidade. Em cada cultura encontramos instituições diferentes, nas quais o homem busca seu próprio interesse vital; costumes diferentes através dos quais ele satisfaz às suas aspirações; diferentes códigos de lei e moralidade que premiam suas virtudes ou punem seus defeitos. Estudar as instituições, costumes e códigos, ou estudar o comportamento e mentalidade do homem, sem atingir os desejos e sentimentos subjetivos pelos quais ele vive, e sem o intuito de compreender o que é para ele, a essência de sua felicidade, [...] perder a maior recompensa que se possa esperar do estudo do homem (MALINOWSKI, 1976, p.38).

Neste sentido, Kubrusly (2006) expõe que a palavra é racional e chega a denominá-la de prolixa e dissertativa; e mais, que ela pode sujeitar, com certa clareza, uma ideia e conceituar com precisão. E aponta também que a imagem como uma emoção direta, de natureza onírica, torna-se insubstituível a um relance da emoção de um evento, mas chama precaução para sua falha na tentativa de analisar fenômenos puramente pela imagem.

E no que tange à espacialidade, Gomes (2013) aponta que há uma questão chave que é a diferença entre olhar e ver. $\mathrm{O}$ último termo abordado seria o que $\mathrm{o}$ 
pesquisador deve realizar em relação ao seu campo visual do objeto em questão, ou seja, notar, sentir e, principalmente, individualizar as coisas dentro do campo formado pelo olhar. E ele evoca cuidado para o lugar físico e o enredo nos quais o objeto é constituído, caracterizando-os com elementos estruturantes para sua compreensão.

E com Dardel (2011, p.9) pode-se compreender que a espacialidade aparece no sentido essencial de qualificação. Esta através de uma "situação concreta que afeta o homem, isso é o que prova a espacialização cotidiana que o espacializa [...]. A distância é experimentada não como uma quantidade, mas como uma qualidade [...]".

Corroborando tal pensamento, Bonsack (2010) argumenta sobre o reconhecimento e o status do sistema presente de referências nas fotografias, os quais influenciam como veículo de informação, pois é estruturada dentro de uma ideologia. E o mesmo autor ainda expõe que "a comunicação sobre as imagens deve ser distinguida do entendimento através de imagens" (Idem, p.115).

E como proposta de conhecer e interagir no ambiente da pesquisa e também de negociar informação com os atores sociais a serem pesquisados, a fotografia de primeira ordem, tem papel fundamental, como mencionou Bourdieu (2013), na entrevista cedida a Franz Shultheir. Ele ressalta que a fotografia em campo é uma forma de o pesquisador demonstrar interesse e valorizar os atores sociais que compõem o campo de pesquisa. No modo de testemunhar suas vidas, e mais, com as fotografias de primeira ordem, podemos rever à vontade, assim como "as gravações, que podemos escutar -, permitem descobrir detalhes que passaram despercebidos à primeira vista e que podemos observar extensamente, a nosso belprazer, durante a pesquisa [...]" (Idem, p. 176).

De tal modo, a fotografia revela e expressa símbolos que estão captados neste conjunto de luzes do modo interno ao presente olhar daquele que a captura. $\mathrm{E}$ estes conjuntos luminosos são construídos por quem registra e pelo grupo social que se deixa registrar. E a fotografia, com isto, não se constitui em algo vazio, mas, principalmente, torna-se fonte de poder que é transferida a quem a capta. $E$, de acordo com Samain (2012, p.24) que, no seguinte trecho sobre a imagem fotográfica menciona: 
[...] é viajante. Ela é cigana e misteriosa. De antemão, ela nos inquieta, sobretudo se ela é uma imagem forte, Istoé, uma imagem que, mais do que tentar impor um pensamento que "forma formata, põe em forma" (o que se denomina "ideologia"), nos coloca em relação com ela. Uma imagem forte é uma forma que pensa e nos ajuda a pensar.

Mediante isto, esta técnica de pesquisa é primordial, pois como um conjunto de atitudes e, principalmente, como uma atividade racional e sistemática, o conhecimento é submetido a uma comprovação, e o pesquisador torna-se "um ativo descobridor do significado das ações e relações que ocultam as estruturas sociais" (CRIZZOTTI, 1995, p.80).

Cervo e Bervian (1978) caracterizam a técnica da fotografia para pesquisa qualitativa como um sistema de proposição duramente corroborado, constante, geral, atrelado entre si pelas relações de condicionamento referente a seres, fatos e fenômenos da experiência. E a ciência torna-se conhecimento apoiada na demonstração e na experimentação, que aceita o que foi aprovado. E mais, trata-se dos poucos aparatos técnicos que alcançam gerações futuras, assim é evocada a fotografia no seu caráter técnico na pesquisa qualitativa.

Dentro deste contexto, a fotografia, na pesquisa qualitativa, encontrou 0 universo rico e encantador da Umbanda, e expos parte da relação com o misticismo através dos Orixás (divindades) e das Entidades Espirituais: dos Caboclos, na representatividade da força e da energia; das Crianças, direcionadas a sua pureza e verdade; dos Pretos-Velhos, com a sua humildade e sabedoria; do Povo do Oriente, com a sua elegância e verdade; e dos Exus, mensageiros de excelência, entidades que possuem atitudes humanas e que têm a função de proteção do espaço sagrado, ou sacralizado pelo indivíduo religioso.

E neste panteão de Orixás e Entidades Espirituais, a Umbanda traz consigo uma linguagem cercada de ritos e símbolos, os quais transformam-se em espacialidades, apresentando formas de manifestações culturais. Assim, as fotografias apresentadas na etapa anterior do texto abarcaram parte deste universo sacralizado e rememorado pelo(s) indivíduo(s), através das festas de homenagem a Xangô e produziu uma "geografia mítica" (DARDEL, 2011, p.48). 


\section{CONSIDERAÇÕES FINAIS}

O perfil exposto neste estudo foi de abordar a fotografia de primeira ordem na pesquisa qualitativa em Geografia Humana para a compreensão da(s) espacialidade(s) contidas nas imagens não como um subproduto dentro da pesquisa ou, muito menos, um mero acessório, mas quanto é uma técnica de significativo aporte científico.

Contribui assim, para um estudo original que apresenta, além do mérito de aproximar o pesquisador do objeto de estudo, também o de dialogar com teóricos das Ciências Sociais, que forneceram, neste estudo, uma fundamentação esclarecedora do objetivo proposto. Assim, este ensaio é destinado àqueles interessados em pesquisa de campo, com a utilização do recurso fotográfico como meio de registro na compreensão da espacialidade, neste caso, da sacralidade dentro da religião da Umbanda.

Neste espectro, os símbolos apresentados pelas imagens são úteis para a ciência geográfica, a qual tem como objeto o estudo do espaço, ou melhor, a atuação do homem e as modificações ocorridas neste sustentáculo humano denominado espaço geográfico.

Desta maneira, justificou-se a importância dos fatores: pesquisa qualitativa, festa religiosa, símbolo e espacialidade, no estudo, pois entende-se que o espaço não é algo vazio, sem vida, é ponto também para a reflexão da visão da espacialidade sobre a devoção. Ele possui um conhecimento que transcende metodologias e, deste modo, o próprio conhecimento humano. Assim, a sumarização das ideias apresentadas servirá como premissa, para estimular futuros questionamentos sobre o tema abordado.

No entanto, a Geografia, por se tratar de uma ciência considerada "multidisciplinar" e, principalmente, que analisa a relação homem/meio, com a finalidade de compreender o objeto de estudo (espaço geográfico). Este palco das efetivações humanas, de modo que o presente encontra-se no passado, por exemplo, através dos fatos que forneceram subsídios para a compreensão de uma dada realidade religiosa no ensaio.

Observou-se que fotografias promoveram o trato do tema e os acordos para as pesquisas da vida religiosa nos Terreiros, em sua plenitude pelo grupo religioso e seus adeptos, não se pode deixar de lado os princípios até aqui sinalizados, correu- 
se o risco de apenas reduzi-lo a uma festividade, mas o que se apresenta é muito mais complexo, é uma fonte de informação e de apresentação, neste universo de devoção, magia e mística das festas em homenagem a Xangô.

Com isto, o estudo procurou também ressaltar a importância das espacialidades simbólicas (religiosas), as quais partem do imaginário humano e ganham forma e sentidos individuais e coletivos, no que se refere aos desdobramentos cultural, social e religioso. Como tarefa, buscou-se trazer contribuições para refleti-la sobre as relações da espacialidade simbólica não como conteúdos de conceitos fechados.

Enfim, este trajeto metodológico foi escolhido, pois confia-se nas relevantes contribuições da imagem fotográfica de primeira ordem, como foram apresentados alguns exemplos de sua aplicabilidade. A ideia também foi de usar o conteúdo fotográfico das pesquisas como modo de demonstrar as manifestações humanas religiosas umbandistas, junto ao diálogo geográfico.

E percebeu-se, claramente, que a utilização da fotografia de primeira ordem na pesquisa qualitativa, evidencia, promove a organização das ações em campo de pesquisas proporcionadas pelos atores sociais pesquisados, pois as diversas imagens e suas qualidades dinamizaram e adequaram emoções, sensações, percepções e raciocínios refletindo-se no modo de sentir, perceber e pensar dos sujeitos (religiosos) em seu meio, ou seja, no seu espaço de permanência com a sacralidade (Terreiro), entre as suas imagens captadas e suas devoções.

\section{REFERÊNCIAS}

BONSACK, R. A compreensão das imagens segundo o método documentário. In: WELLER, W.; PFAFF, N. (Orgs.). Metodologia da Pesquisa Qualitativa em Educação. Rio de Janeiro: Vozes, 2010. p. 114-134.

BOURDIEU, P. A Economia das Trocas Simbólicas. Tradução de Sergio Miceli. 6. ed. São Paulo: Perspectiva, 2009.

Argélia na Mira. (entrevista). ZUM. Revista de fotografia. Instituto Moreira Sales, abril 2013. p. 160-177.

CERVO, A. L.; BERVIAN, P. A. Metodologia científica: para uso dos estudantes universitários. 2. ed. São Paulo: McGraw-Hill do Brasil, 1978. 
CRIZZOTTI, A. Pesquisa em ciências humanas e sociais. 2. ed. São Paulo: Cortez, 1995.

DARDEL, E. O homem e a terra: natureza da realidade geográfica. Tradução de Werther Holzer. São Paulo: Perspectiva, 2011.

ELIADE, M. Mito e realidade. Tradução de Paola Civelli. São Paulo: Perspectiva, 2010.

GOMES, P. C. C. O lugar do olhar. Rio de Janeiro: Bertrand Brasil, 2013.

KUBRUSLY, C. A. O que é fotografia. 4. ed. São Paulo: Brasiliense, 2006.

MALINOWSKI, B. Tema, método e objetivo desta pesquisa. In:

Argonautas do Pacífico Ocidental. Tradução de Anton P. Carr e Ligia Aparecida Cardieri Mendonça. Coleção os pensadores. Ed. Abril, 1976. p. 21-39.

PRANDI, R. Xangô. In: . Mitologia dos Orixás. São Paulo: Companhia das Letras, 2001. p. 242-291.

SAMAIN, E. Como pensam as imagens. Campinas: Ed. Unicamp, 2012.

(Recebido em 04.02.2014. Aceito em: 14.06.2014) 